\section{OAK RIDGE} NATIONAL

LABORATORY

UT-Battelle
Supplemental Release Limits for the Directed Reuse of Lead in Shielding Products by the Department of Energy

\author{
R. L. Coleman and J. S. Bogard \\ Life Sciences Division
}




\title{
Supplemental Release Limits for the Directed Reuse of Lead in Shielding Products by the Department of Energy
}

\author{
R. L. Coleman and J. S. Bogard \\ Life Sciences Division
}

August 2001

\author{
Prepared for the \\ National Center of Excellence for Metal Recycle \\ U. S. Department of Energy \\ Prepared by \\ OAK RIDGE NATIONAL LABORATORY \\ P.O. Box 2008 \\ Oak Ridge, Tennessee 37831-6285 \\ managed by \\ UT-Battelle, LLC \\ for the \\ U.S. DEPARTMENT OF ENERGY \\ under contract DE-AC05-00OR22725
}




\title{
DOCUMENT AVAILABILITY [DOES NOT APPLY TO DRAFT DOCUMENTS]
}

Reports produced after January 1, 1996, are generally available free via the U.S. Department of Energy (DOE) Information Bridge:

Web site: http://www.osti.gov/bridge

Reports produced before January 1, 1996, may be purchased by members of the public from the following source:

\author{
National Technical Information Service \\ 5285 Port Royal Road \\ Springfield, VA 22161 \\ Telephone: 703-605-6000 (1-800-553-6847) \\ TDD: 703-487-4639 \\ Fax: 703-605-6900 \\ E-mail: info@ntis.fedworld.gov \\ Web site: http://www.ntis.gov/support/ordernowabout.htm
}

Reports are available to DOE employees, DOE contractors, Energy Technology Data Exchange (ETDE) representatives, and International Nuclear Information System (INIS) representatives from the following source:

Office of Scientific and Technical Information

P.O. Box 62

Oak Ridge, TN 37831

Telephone: 865-576-8401

Fax: 865-576-5728

E-mail: reports@adonis.osti.gov

Web site: http://www.osti.gov/contact.html

This report was prepared as an account of work sponsored by an agency of the United States Government. Neither the United States government nor any agency thereof, nor any of their employees, makes any warranty, express or implied, or assumes any legal liability or responsibility for the accuracy, completeness, or usefulness of any information, apparatus, product, or process disclosed, or represents that its use would not infringe privately owned rights. Reference herein to any specific commercial product, process, or service by trade name, trademark, manufacturer, or otherwise, does not necessarily constitute or imply its endorsement, recommendation, or favoring by the United States Government or any agency thereof. The views and opinions of authors expressed herein do not necessarily state or reflect those of the United States Government or any agency thereof. 


\section{CONTENTS}

ACKNOWLEDGMENTS $\ldots \ldots \ldots \ldots \ldots \ldots \ldots \ldots \ldots \ldots \ldots \ldots \ldots \ldots \ldots$

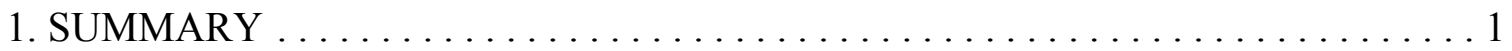

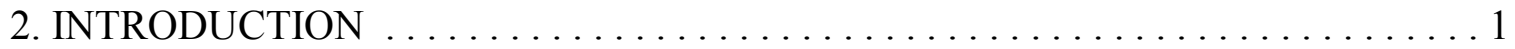

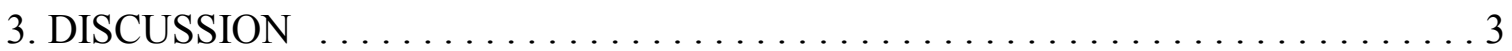

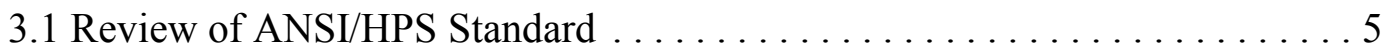

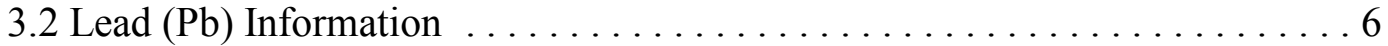

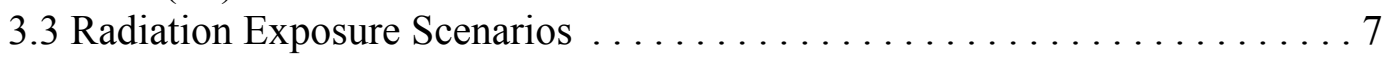

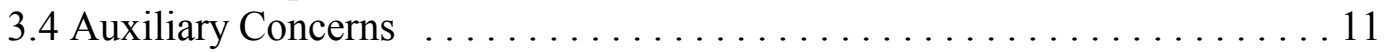

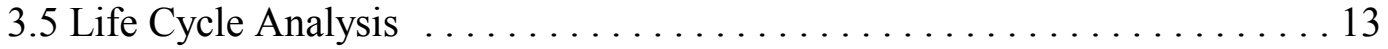

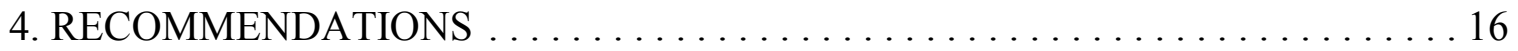

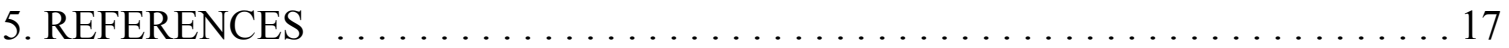

Table 1. Recommended Supplemental Release Limits . . . . . . . . . . . . . . . . . 19

Figure 1. Comparison of alternatives for disposition of DOE contaminated $\mathrm{Pb} \ldots \ldots 20$

Appendix 1. Commercial Sector Contaminated Lead Recycling Initiative . . . . . . A1-1 


\section{ACKNOWLEDGMENTS}

The authors wish to acknowledge the support, introductory text and comments provided by M. Lee Bishop of the Department of Energy, as well as review comments provided by Eric W. Abelquist of the Oak Ridge Institute for Science and Education. The authors also wish to thank Christine M. R. Goddard of IT Corporation for the cost analysis included in the life-cycle evaluation. 


\section{SUMMARY}

The DOE National Center of Excellence for Metals Recycle (NMR) proposes to define and implement a complex-wide directed reuse strategy for surplus radiologically impacted lead $(\mathrm{Pb})$ as part of the U.S. Department of Energy's commitment to the safe and cost-effective recycle or reuse of excess materials and equipment across the DOE complex. NMR will, under this proposal, act on behalf of the DOE Office of Environmental Management, Office of Technical Program Integration (specifically EM-22), as the Department's clearinghouse for DOE surplus lead and lead products by developing and maintaining a cost-effective commercially-based contaminated lead recycle program. It is NMR's intention, through this directed reuse strategy, to mitigate the adverse environmental and economic consequences of managing surplus lead as a waste within the complex. This approach would promote the safe and cost-effective reuse of DOE's scrap and surplus lead in support of the Department's goals of resource utilization, energy conservation, pollution prevention and waste minimization.

This report discusses recommendations for supplemental radiological limits for the directed reuse of contaminated lead and lead products by the DOE within the nuclear industry. The limits were selected - with slight modification - from the recently published American National Standards Institute and Health Physics Society standard N13.12 titled Surface and Volume Radioactivity Standards for Clearance (ANSI/HPS 1999) and are being submitted for formal approval by the DOE. Health and measurement implications from the adoption and use of the limits for directed reuse scenarios are discussed within this report.

\section{INTRODUCTION}

Directed reuse and recycling strategies are being developed by the Facilities and Materials Reuse Division at Oak Ridge Operations (ORO) to address former Secretary of Energy Richardson's July 13, 2000 memorandum establishing a suspension on releasing the Department's scrap metals from radiological areas into open commerce and the previous January 2000 Secretarial moratorium on the release of volume-contaminated metal. Such strategies, which fully conform to the Secretarial policy initiatives, and which are supported by DOE legal, property management, and project management policies and procedures, have been proposed for directed reuse of radiologically contaminated lead.

DOE sites now routinely purchase clean lead products (bricks, sheet, and components), available commercially at a cost of over $\$ 1$ pound, for use in reactors, accelerators and radiological facilities. An uncontaminated lead product may be recycled or disposed of as a hazardous waste under the Resource Conservation and Recovery Act (RCRA) at the end of its useful life, but lead which has become radioactively contaminated must be disposed of as mixed waste-being regulated as both a RCRA and as a

radiologically controlled material. The only disposal option for radiologically impacted lead 
at this time is burial following macro encapsulation at a cost of $\$ 1.50-\$ 3.00$ per pound at Envirocare, Hanford or the Nevada Test Site (NTS).

The Office of Energy Research estimates that DOE sites have about 2.1M kg $(2,100$ tonnes) of contaminated lead in inventory and an additional $4 \mathrm{M}-24 \mathrm{M} \mathrm{kg}(4,000-$ 24,000 tonnes) of waste lead, much of which may be radioactively contaminated. Additional contaminated lead, currently not accounted for in the above figures, will be generated as the result of decontamination and decommissioning of radiological facilities at DOE sites. The cost and environmental impact for treatment and burial of radioactively contaminated lead as a mixed waste poses a significant liability to the DOE.

The DOE National Center of Excellence for Metals Recycle (NMR) proposes to define and implement a complex-wide internally-controlled directed reuse strategy for surplus radiologically impacted lead as part of the U.S. Department of Energy's commitment to the safe and cost-effective recycle or reuse of excess materials and equipment generated within the DOE complex. NMR will, under this proposal, act on behalf of the DOE Office of Environmental Management, Office of Technical Program Integration (specifically EM22), as the Department's clearinghouse for DOE surplus lead and lead products by developing and maintaining a cost-effective commercially-based contaminated lead recycle program. It is NMR's intention, through this directed reuse strategy, to mitigate the adverse environmental and economic consequences of managing surplus lead as a waste within the complex. This approach would promote the safe and cost-effective reuse of DOE's scrap and surplus lead in support of the Department's goals of resource utilization, energy conservation, pollution prevention and waste minimization.

The proposed lead reuse strategy would require Department Field Elements to consider first the reuse of existing lead inventories prior to procuring new lead or lead products. DOE sites with lead in the disposal queue would also be required to redirect disposal-related funding to recycling and reuse of the lead into usable products. Sites must also be able to accept and use lead products with very low levels of volumetric radioactive contamination instead of purchasing new lead.

Incorporating radioactively contaminated lead as shielding for storage disposal containers is envisioned as a principal means of reusing this material within DOE with a high degree of safety and control. A need for such containers has been identified by many DOE sites and programs. Shielded disposal containers would be fabricated by decanting molten $\mathrm{Pb}$ into a range of twin-walled vessels (such as 7A Type-A waste disposal containers, strong tight containers, and modular shield wall components). Associated costs are believed to be less than those necessary for disposal of the $\mathrm{Pb}$ as a mixed waste. The most likely alternative to the proposed recycling of impacted lead would be direct disposal as mixed waste. This alternative would be less attractive from an environmental perspective, would be more costly and would also be a less responsible use of a natural resource. 
The term directed reuse is used throughout this report to describe the controlled deployment of $\mathrm{Pb}$ shielding products solely within the nuclear industry following initial production. As such, the DOE may direct the products for use either within its own complex or at commercial licensee sites. The supplemental release limits recommended within this report were determined to meet DOE requirements for protection of the public consistent with DOE's As Low As Reasonably Achievable (ALARA) requirements. The limits are generally consistent with the recommended screening levels for unconditional clearance of materials to the general public provided in the ANSI N13.12-1999 Standard-which were developed to provide a reasonable expectation that public dose from uncontrolled releases would not exceed $1 \mathrm{mrem}$ in a year. Under this DOE Authorized release for direct reuse, public exposures would be even lower or, considering the expected uses, almost nonexistent.

The following sections describe radiological limits recommended for internal directed reuse of contaminated lead and lead products within DOE as well as a qualitative comparison to the direct disposal alternative. The limits are based on existing regulatory limits and national standards for releasing materials with surface and volumetric radiological contamination. Public health implications from the adoption and use of the recommended limits for the internal directed reuse scenario are also discussed.

\section{DISCUSSION}

The purpose of this analysis is to support the development of DOE-approved limits for the directed reuse and recycling of lead that may contain slight concentrations of residual radioactive material. The basis for recommended limits may be found in the recently published American National Standards Institute and Health Physics Society standard N13.12 (ANSI/HPS 1999) — Surface and Volume Radioactivity Standards for Clearance. This standard was developed under the direction of the Health Physics Society by the ANSIaccredited HPS N13 Committee and provides recommended screening levels for the release of potentially contaminated materials and equipment for unconditional use. The standard recommends de-minimis release criteria for unconditional reuse for materials that could be contaminated volumetrically or on their surfaces - however their appliction in this action is being proposed for directed reuse.

Although the ANSI N13.12 standard provides recommended limits for unrestricted release, the Department has not approved them for generic application and their use requires case-by-case approval by the DOE. Limits for unrestricted (public) use would simplify the release process and allow the lead to be used for purposes other than shielding products. This is not being considered, however, because it is inconsistent with the present DOE suspension on the recycling of metal from radiological areas. 
The supplemental limit is being proposed because DOE surface activity guidelines ${ }^{(1)}$ are not adequate to address the lead reuse process. In such conditions, DOE requires the development of specific authorized or supplemental limits for the release. In this analysis, it is being proposed that the ANSI N13.12 standards (with one modification for Group 4 radionuclides) be adopted because they contain both surface and volumetric standards and are risk based. Alternative approaches were considered and rejected as follows.

Alternative I-Higher Limits: Because the proposed supplemental limit is for directed recycle, it is possible that DOE could establish limits that allow higher concentrations of residual radioactive material in the lead then would be allowed by ANSI N13.12(2). DOE considered the pros and cons of allowing higher levels but concluded that increasing the limits would not produce a commensurate benefit. Raising the limit would not significantly affect the potential public radiological hazard and would also not significantly increase the quantity of lead available for reuse. Although measurement and associated survey requirements may be easier to implement, this potential benefit was also deemed to be insignificant. Additionally, the use of alternative criteria that are greater than the ANSI N13.12 criteria would require additional resource commitments to conduct the assessments. Based on a qualitative review of this option it was decided that there was not a commensurate benefit for health, the environment or for program implementation aspects. The Department therefore concluded that there was no value in considering this alternative further at this time.

Alternative II-Lower Limits: DOE considered criteria that would be more stringent than the ANSI N13.12 standard. As noted, ANSI N13.12 clearance screening levels are for unrestricted clearance and provide reasonable confidence that the incremental dose to an individual member of the public will be very small (i.e., less than $1 \mathrm{mrem} / \mathrm{y}$ ). As such, there is no public health or environmental benefit to be observed by adopting limits below the ANSI N13.12 screening levels. From a program implementation perspective, if the limits were lowered substantially there could be a significant reduction in the amount of lead available for reuse, while measurement difficulties could substantially increase costs and adversely impact resources of the program. As part of a multi-attribute analysis conducted to insure that the supplemental limits are consistent with DOE ALARA requirements (Sections 3.4 and 3.5), the Department determined that reducing the Group 4 (beta-gamma emitters) screening levels to $1000 \mathrm{pCi} / \mathrm{g}$ from $3000 \mathrm{pCi} / \mathrm{g}$ would provide additional assurance that containers manufactured under the proposed program would avoid conflict with existing

${ }^{(1)}$ DOE 5400.5 permits the use of the DOE surface activity guidelines as authorized limits for the unrestricted release of property. Although the recent DOE policy to suspend unrestricted recycling of metal prohibits releases into commerce of metal from radiological areas, the surface guidelines may still be used for restricted release.

(2) N13.12 presumes unrestricted use of the released material and its limits provide reasonable assurance that dose releases will be less than $1 \mathrm{mrem} / \mathrm{y}$. Therefore, it is reasonable to conclude that less restrictive limits may be possible if analysis was performed specifically for controlled reuse scenarios. 
Department of Transportation (DOT) requirements. For this specific set of radionuclides, measurement capability would not be significantly affected.

\subsection{Review of ANSI/HPS Standard}

The ANSI/HPS N13.12 standard is "intended to provide guidance for protecting the public and the environment from radiation exposure by recommending a primary radiation dose criterion and derived screening levels for the clearance of items that could contain radioactive material". The intent is purely for application to items or materials that may contain residual radioactive materials above those naturally found in such materials and does not apply to naturally-occurring background radionuclides - other than those that have been concentrated by human technology.

The primary bounding condition used within the standard is a dose criterion of $1 \mathrm{mrem} / \mathrm{y}(0.01 \mathrm{mSv} / \mathrm{y})$ to the average member of a critical group. Scenarios for direct-reuse, disposal and public recycle are considered. The analysis incorporates the as-low-asreasonably-achievable (ALARA) philosophy with the intent of balancing the primary dose criterion with detection issues as well as background exposure to natural sources. The result is a table of recommended free-release screening levels for a broad range of common radionuclides. Levels are given for materials contaminated either volumetrically or on their surfaces - with surface criteria given as a constant ratio to those given for volumetric contamination. When more than one radioisotope is present, a unity rule applies.

Important issues arise when considering ANSI/HPS N13.12 as a technical basis for recommending limits for the directed reuse of $\mathrm{Pb}$ in shielding containers. Previous studies referenced within N13.12 primarily consider the unconditional release of steel and have usually found that maximally exposed individuals are those employed during initial processing tasks - such as steel workers at processing facilities. The proposed shielding containers will be processed and built by a contractor regulated by the Nuclear Regulatory Commission (NRC), the DOE or an Agreement State and will require radiological controls during initial processing and fabrication. Following manufacture, shield products are intended for use at nuclear facilities, whereas ANSI/HPS N13.12 criteria were established assuming unconditional release and uncontrolled use.

Another distinct issue is that $\mathrm{Pb}$ is a chemical toxin and has exposure risks separate from those that may be added by the presence of residual radioactive materials. This fact must be considered parallel to evaluations of incremental hazard due to the presence of radioactive materials. Finally, $\mathrm{Pb}$ is used in a more narrow range of public products than steel or other commodity metals thereby limiting the number of potential exposure scenarios if $\mathrm{Pb}$ products were unintentionally released for public recycle or reuse.

Implementation guidance is also provided within ANSI/HPS N13.12 and discusses topics such as process knowledge, instrumentation selection and measurement considerations. Process knowledge generally refers to all historical information that can be 
documented about a material and is very useful when considering disposition alternatives prior to reuse or release. Unfortunately, historical information usually lacks the detail required for confirming radiological criteria, and pre-release measurements are typically required. Detection sensitivity for surface and volumetric measurements was an important consideration when the recommended derived screening levels were selected, and discussions for each are provided.

As a final note related to the selection of volumetric limits, the standard states that "items known to be contaminated at activity levels that are in excess of the clearance screening levels should not be: a) intentionally blended with lower specific activity material, or b) intentionally coated, plated or covered to reduce apparent surface contamination". This statement was included to emphasize that the mixing of contaminated and "clean" materials is not justified by monetary interest. Although doing so may be perfectly safe, it is considered to be a poor use of natural resources and is therefore not viewed to be acceptable.

\subsection{Lead (Pb) Information}

Lead, a naturally occurring primordial element, is one of the first metals to have been used (dating back to $6500 \mathrm{BC}$ ) by humans. Lead is indispensable to many industries because of its natural properties, which include high density, easy malleability, low melting point, corrosion resistance and high electrical conductivity. Because $\mathrm{Pb}$ is easily re-melted and refined, it has the highest recycling rate of all industrial metals in the world.

Demand for refined lead in the U. S. in 1998 was $1.6 \times 10^{6}$ tonne (AMMC, 2000) and has grown by an average of just over $4.0 \times 10^{3}$ tonnes/y over the last decade. A simple forecast using these values predicts that demand for lead in 2001 will therefore be about $1.7 \times 10^{6}$ tonne. Most of this lead will be used in transportation (76\%) of which a significant portion will be obtained from recycled metal (71\%). More than $95 \%$ of automotive batteries, which account for $80 \%$ of $\mathrm{Pb}$ consumption in the U. S., are recycled.

Electrical storage batteries of all types accounted for $87.4 \%$ of $\mathrm{Pb}$ used in the U.S. in 1997 (AMMC, 2000). Ammunition, shot and bullets account for about 3.5\% of U.S. Pb products; sheet $\mathrm{Pb}$ and casting metal, 1.2\% each; and $\mathrm{Pb}$ oxides, $4.2 \%$. Other $\mathrm{Pb}$ product types accounting for lesser percentages include bearing metals $(0.2 \%)$; brass and bronze, billets and ingots $(0.3 \%)$; cable covering, power and communication $(0.3 \%)$; calking $\mathrm{Pb}$, building construction $(0.1 \%)$; pipes, traps and other extruded products $(0.1 \%)$; solder $(0.6 \%)$; type metal and other metal products ${ }^{(3)}(0.5 \%)$; and miscellaneous uses $(0.5 \%)$.

The density, malleability and corrosion resistance of $\mathrm{Pb}$ make it an outstanding material for radiation shielding applications. Lead is more effective than iron or steel in

\footnotetext{
(3) Includes $\mathrm{Pb}$ consumed in foil, collapsible tubes, annealing, plating, galvanizing and fishing weights.
} 
shielding gamma and X radiation (Hubbell and Seltzer, 1997), both because it is more dense and because of its higher atomic number. A 0.75 -inch lead shield, for example, is $32 \%$ more effective than the same thickness of iron in absorbing energy of 1.17- and 1.33-MeV photon emissions from ${ }^{60} \mathrm{Co}$, and $21 \%$ more effective in absorbing energy from $2.61-\mathrm{MeV}$ photons emitted by Tl-208.

Elemental lead and many of its compounds are toxic to both humans and animals at elevated levels. The young have a higher fractional uptake ability for lead following intake and are particularly susceptible to toxic effects, which include decreased intelligence quotients (IQs) and stunted growth. Trans-placental exposure of the embryo or fetus can cause premature birth, lower birth weight, and decreased mental ability in the infant. Excessive lead exposure in adults can result in decreased reaction time, possible memory effects, weakness in extremities, anemia, and elevated blood pressure. Exposure to high levels of lead can cause damage to the male reproductive system, abortion in pregnant women, and can severely damage the brain and kidneys (USDHHS, 1993a). The American Conference of Governmental Industrial Hygienists (ACGIH) has recommended a timeweighted average (TWA) of $0.05 \mathrm{mg} / \mathrm{m}^{3}$ as the Threshold Limit Value (TLV) for occupational exposure to elemental and inorganic lead in air (ACGIH, 1996).

Environmental lead is ubiquitous, primarily because of human activity. The use of lead in automobile fuel additives prior to December 31, 1995, is responsible for most of the environmentally available lead today (USDHHS, 1993a). About $51 \%$ of lead solid waste has, in the past, been spent ammunition and ordnance (USEPA, 1982). Lead shot used for hunting waterfowl is now prohibited because of its toxicity to birds that are wounded but not killed and to wildlife that might ingest the loose shot. Federal law specifies the use of non-toxic shot, instead, for taking migratory waterfowl (50CFR, 1997). The metal and many lead compounds, including oxides, are listed as Hazardous Wastes by the U.S. Environmental Protection Agency (EPA) (40CFR, 1997).

\subsection{Radiation Exposure Scenarios}

The screening values given in HPS/ANSI N13.12 were selected based on public exposure scenarios and were primarily concerned with contaminated steel. This section provides a few brief discussions for plausible exposure scenarios that could be associated with internally recycled $\mathrm{Pb}$ products and includes scripts for internal worker usage as well as a review of unintentional release to the public. The DOE process for supplemental limits that encompass restrictions also require that DOE consider the consequences of failure of the restrictions. As a result, this section also includes a review of some potential consequences (exposures) that might result should restrictions fail.

Under the proposed recycle and reuse scenario there is little to no mechanism for public exposure to the product without failure of control. It is required that the products be used as shielding at nuclear facilities and that they not be readily available to the public throughout their life cycle. Potential visitors to shipping, waste handling and disposal sites 
must be managed according to DOE access and health protection requirements and will have no significant pathway of exposure. Although the ANSI N13.12 screening criteria are based on a possible $1 \mathrm{mrem} / \mathrm{y}$ public dose for unrestricted use, the addition of the restrictions associated with the dedicated-use supplemental limit reduce the potential for public dose-during the restricted reuse cycle - to an almost non-existent level.

\section{Initial Reprocessing}

This proposal is intended for the controlled recycle and reuse of $\mathrm{Pb}$, and therefore all initial processing will be performed at either a DOE site or an NRC-licensed facility under agreement with the DOE. Worker protection, consistent with DOE or NRC occupational radiological exposure requirements, must be met separately.

\section{DOE Shield Use}

A primary anticipated use for products built using recycled $\mathrm{Pb}$ is internal, directed reuse as shielding within waste containers. Since DOE requires that all work be performed in accordance with requirements stipulated in 10 CFR Part 835-Occupational Radiation Protection, internal reuse evaluation is not really necessary. However, to provide estimates of worker exposure impacts by unregulated products, a $\mathrm{Pb}$-lined waste container scenario is reviewed.

Consider a B25 disposal container that has a $3 / 4$-inch thick $\mathrm{Pb}$ liner within all six walls. Such a container will have overall nominal outside dimensions of 4-feet wide by 4feet high by 6 -feet long - although actual dimensions may be slightly different. The $\mathrm{Pb}$ liner will be contained within a welded steel cavity with no immediate access by direct contact so the most significant means of exposure will be direct external radiation from gamma emitters.

The box is assumed to contain a liner made from reprocessed $\mathrm{Pb}$ containing residual levels of ${ }^{60} \mathrm{Co}$ at the HPS/ANSI N13.12 recommended screening level of $30 \mathrm{pCi} / \mathrm{g}$. The liner is $3 / 4$-inches thick, is present at contact with all six walls and is encased in $1 / 8$-inches of steel on all sides. Using the computer code Microshield ${ }^{\mathrm{TM}}$, the exposure rate at the surface of such a container was estimated to be approximately $20 \mu \mathrm{R} / \mathrm{h}(0.02 \mathrm{mR} / \mathrm{h})$. If a worker were to spend $2 \%$ of his work time-i.e., 40 hours per year-within close proximity to two such containers on opposing sides, the annual occupational effective dose equivalent (EDE) could be $\sim 2$ mrem. Considering that the containers would presumably be used for storing radioactive materials and would therefore have auxiliary worker controls in place, this scenario is considered to be a reasonable upper-bound estimate for worker exposure from $\mathrm{Pb}$ shielding products. As simple points of comparison, the estimated upper-bound EDE of 2 mrem is much less than the DOE annual occupational dose limit of 5000 mrem and only about $1 \%$ of the average annual dose received from natural background. 


\section{Unintentional Entry of Final Products into the Public}

The proposed shield products are intended solely for restricted use within the nuclear industry and, as discussed earlier, there is no significant pathway for public exposure. It is required, however, to consider the possibility that some of these products may become accessible to the public in the future. Two scenarios are considered for qualitative discussion. The first, and arguably least likely, is that a shielded waste container product is disassembled and reused without intermediate processing. The second, unplanned but subjectively more plausible, scenario is that shielding products are taken into commerce and blended into existing streams of recycled $\mathrm{Pb}$.

\section{Direct handling}

Consider that a metals salvage company acquires — by some means - products that have been built using DOE-recycled $\mathrm{Pb}$. One would prefer to assume that persons involved with such an effort would be aware of the toxic properties of $\mathrm{Pb}$ and would therefore exercise health protective measures. It is assumed that this will not be the case for the sake of postulating a worse-case plausible scenario and the hazard associated with radioactive material burden is considered relative to chemical toxicity.

It is first assumed that a person processing $\mathrm{Pb}$ does not employ protective measures and that the suspect shield product contains ${ }^{239} \mathrm{Pu}$ at the HPS/ANSI recommended screening level of $3 \mathrm{pCi} / \mathrm{g}$. This would mean that, for each $\mu \mathrm{g}$ of $\mathrm{Pb}$ volatilized into the air, $3 \times 10^{-12}$ $\mu \mathrm{Ci}$ of $\mathrm{Pu}\left(\sim 5 \times 10^{-11} \mathrm{~g}\right)$ would also be vaporized. Assuming a breathing-zone dilution volume of $9 \mathrm{~m}^{3}$ leads to a calculated local air concentration of $3 \times 10^{-19} \mu \mathrm{Ci} / \mathrm{cm}^{3}$ per $\mu \mathrm{g}$ of volatilized $\mathrm{Pb}$. Selecting a derived air concentration (DAC) for a Y-Class compound of ${ }^{239} \mathrm{Pu}$ yields $7 \times 10^{-12} \mu \mathrm{Ci} / \mathrm{cm}^{3}$ (EPA/Eckerman et al 1988). Assuming that the scenario would be limited in extent and could not lead to an exposure duration in excess of $20 \%$ of a person's work year (400 hours) allows the calculation of a committed effective dose equivalent coefficient of $\sim 5 \times 10^{-8}$ rem per $\mu \mathrm{g}$ of $\mathrm{Pb}$ volatilized.

Citing hazard control guidance presented in Section 3.2- $\mathrm{Pb}$ Information, the ACGIH time-weighted average (TWA) Threshold Limit Value (TLV) is $0.05 \mathrm{mg} / \mathrm{m}^{3}$ for occupational exposure to elemental and inorganic lead in air. If a person were to be exposed at this concentration with a concomitant burden of ${ }^{239} \mathrm{Pu}$ at $3 \mathrm{pCi} / \mathrm{g}$ for $20 \%$ of a work year, the committed effective dose equivalent would be $\sim 2 \times 10^{-2} \mathrm{mrem}$. It is therefore asserted, without direct analysis of other internal exposure routes, that the radiological consequence will be very small when worker exposures are controlled relative to $\mathrm{Pb}$ chemical toxicity guidelines.

Referring to the previous analysis for $\mathrm{Pb}$ shielding containers and occupational workers, a quick evaluation of external exposure during the public reuse scenario can be performed. Assuming that a $\mathrm{Pb}$ salvage worker were to somehow acquire enough product material to require $5 \%$ of their work time during a 1 -year period (100 hours) performing close-proximity tasks with single containers, then the external dose equivalent would be 
$\sim 2$ mrem - far below dose limits established for public protection. Note again that this estimate assumes a $100 \%$ burden of ${ }^{60} \mathrm{Co}$ at $30 \mathrm{pCi} / \mathrm{g}$ within the $\mathrm{Pb}$ material.

\section{Public Recycle}

It is prudent to consider that a modest quantity of $\mathrm{Pb}$ shielding product could leave controlled use and be blended into the $\mathrm{U}$. S. stream of recycled $\mathrm{Pb}$ at some future time. Public recycle of metals was a core consideration within studies referenced by the ANSI/HPS N13.12 working committee when establishing the recommended screening criteria. A significant point however is that these studies were primarily focused on evaluating the recycle of steel and that the model parameters were selected for this purpose. A quantitative analysis of the pathway for $\mathrm{Pb}$ is beyond the scope of this report, however it is believed that the outcome of such an analysis - if performed - would indicate maximum individual doses at or below those referenced for steel. Significant premises for this statement are that: $\mathrm{a}) \mathrm{Pb}$ materials and contaminants would have been well blended during initial DOE recycle operations and would therefore significantly limit the potential for internal exposures during re-processing by workers; b) worker protection protocols are used during $\mathrm{Pb}$ processing due to its toxic nature; and c) public products for $\mathrm{Pb}$ are limited — with the primary use being automobile batteries.

Considering that the most likely end-product for public use would be an automobile battery, an analysis for this scenario was briefly considered. It is emphasized yet again that such a scenario is unlikely and is only presented for illuminating the possible exposure consequence that would be associated with such an occurrence. Forward-referencing information provided in Section 3.4-Impact on the quality of the U.S. Pb supply, an estimated initial dilution factor for lead passed through a public recycle channel is assumed to be approximately $10^{-3}$. This means that the concentration in a hypothetical car battery - manufactured from $\mathrm{Pb}$ that had been tainted with DOE shielding product during a public recycle operation - could contain one part in one thousand at the authorized release limit concentration. For ${ }^{60} \mathrm{Co}$, this would correlate to an overall bulk concentration of about $0.03 \mathrm{pCi} / \mathrm{g}$. Such a low concentration is hardly worthy of concern as an external exposure hazard but is considered nonetheless.

Assume that a $1 \times 10^{4} \mathrm{~cm}^{3}\left(\sim 600 \mathrm{in}^{3}\right)$ battery has been manufactured and is placed into a personal automobile. Further assume that the auto is driven for three hours per day and that the driver's torso sits at a radial distance of about 1.5 meters from the battery center. Since the amount of steel between these two points can vary greatly depending on the automobile design, it is conservatively removed from consideration altogether. Considering a residual burden of ${ }^{60} \mathrm{Co}$ at a concentration of $0.03 \mathrm{pCi} / \mathrm{g}$, the effective dose equivalent rate at the drivers position would be $\sim 2 \times 10^{-8} \mathrm{mrem} / \mathrm{h}$ and the annual effective dose equivalent to the driver would be approximately $\sim 2 \times 10^{-5} \mathrm{mrem}$. Using this result as a realistic basis it can be seen that, even if a battery was manufactured directly from shield product without any intermediate dilution - i.e., with residual ${ }^{60} \mathrm{Co}$ at the maximum recommended release limit of $30 \mathrm{pCi} / \mathrm{g}$ - that the total annual dose equivalent for the driver would only be about $0.02 \mathrm{mrem}$. 
Along a similar vein of evaluating hypothetical but plausible scenarios, consider a twenty-inch (dia) display cathode-ray-tube (CRT) used as part of a computer workstation monitor. Such a CRT will be made of a mixture of different types of glass, with the back portions - called the neck and funnel-consisting of up to $25 \mathrm{wt} \% \mathrm{~Pb}$ for the supposed purpose of shielding $\mathrm{x}$-rays produced from electrons accelerated within the tube (Townsend, 1999). A glass solder - called frit - is used to connect the front panel to these back portions during the manufacture of a color CRT and will contain about $70 \mathrm{wt} . \% \mathrm{~Pb}$. The front viewing panel of such a monitor will typically contain anywhere from zero up to $3 \mathrm{wt} . \% \mathrm{~Pb}$, although some manufacturers have begun removing $\mathrm{Pb}$ from this portion altogether. Since the front panel must be relatively thick in order to withstand atmospheric pressures against internal vacuum, the glass acts as a sufficient $\mathrm{x}$-ray shield for the frontal region.

The quantity of $\mathrm{Pb}$ present in a display can vary considerably so, for this analysis, a scenario is selected where a monitor contains $2.5 \mathrm{~kg}(5.5 \mathrm{lbs})$ of $\mathrm{Pb}$ - with almost all of this mass located within the funnel and neck portions of the tube. A user is assumed to sit at a horizontal distance of $60-\mathrm{cm}$ (24-in) from the front panel of such a monitor and that it has been manufactured using re-processed lead containing residual ${ }^{60} \mathrm{Co}$ at an initial concentration of $0.03 \mathrm{pCi} / \mathrm{g}$. Assuming a $1-\mathrm{cm}$ thick front glass panel, the dose equivalent rate at 24-inches perpendicular to the face of the monitor was calculated to be approximately $2 \times 10^{-7} \mathrm{mrem} / \mathrm{h}$. If a person were to be exposed at this rate for 8 hours per day, 250 days per year, the annual effective dose equivalent would be about $4 \times 10^{-4} \mathrm{mrem}$. Extending this correlation to a hypothetical case where a display monitor has been constructed using $\mathrm{Pb}$ which has not been diluted through a public recycle channel, the maximum annual effective dose equivalent would be $\sim 0.4$ mrem.

\subsection{Auxiliary Concerns}

Measurement Sensitivity - As discussed within HPS/ANSI N13.12, measurement sensitivity is a key component when selecting release criteria. Recommended surface contamination screening levels within the guidance are detectable using commercially available detection systems, however an evaluation of measurements associated with volumetrically contaminated $\mathrm{Pb}$ was not considered.

Taking a qualitative perspective, one can quickly delineate volumetric measurement methods into three broad categories for gamma-emitting, beta-emitting and alpha-emitting radionuclides. Of these, gamma-emitting radionuclides are typically the easiest to quantify - even when the host medium is $\mathrm{Pb}$. Detection ability for some common gammaemitting radionuclides using gamma spectrometry with a $50 \%_{[3 \times 3 \mathrm{Nar}]} \mathrm{HPGe}$ coaxial detector were estimated at recommended screening levels for a $1-\mathrm{cm}^{3} \mathrm{~Pb}$ aliquot. The results are presented in the following table. 


\begin{tabular}{l|c|c}
\hline \multicolumn{1}{c|}{$\begin{array}{c}\text { Isotope }{ }^{(1)} \\
(\gamma \text {-Energy Range) }\end{array}$} & $\begin{array}{c}\text { Screening } \\
\text { Level } \\
(\mathrm{pCi} / \mathrm{g})\end{array}$ & $\begin{array}{c}\text { Measurable using } \\
\text { 4-hour acquisition } \\
\text { with a 50\% HPGe? }{ }^{(2)}\end{array}$ \\
\hline${ }^{241} \mathrm{Am}(60 \mathrm{keV})$ & 3 & No \\
${ }^{226} \mathrm{Ra}(47$ to $1764 \mathrm{keV})$ & 3 & Yes \\
${ }^{238} \mathrm{U}(63$ to $1001 \mathrm{keV})$ & 30 & No \\
${ }^{235} \mathrm{U}(84$ to $205 \mathrm{keV})$ & 30 & Yes \\
${ }^{137} \mathrm{Cs}(662 \mathrm{keV})$ & 30 & Yes \\
${ }^{60} \mathrm{Co}(1173$ to $1332 \mathrm{keV})$ & 30 & Yes \\
\hline
\end{tabular}

(1) Energies are approximate, include emissions from short-lived daughters and exclude minor energy lines.

(2) Assumes a coaxial-design HPGe detector with an intrinsic efficiency at $50 \%$ of what would be expected from a 3"x 3" cylindrical NaI(Tl).

Wet-chemistry methods would be required for $\mathrm{Pb}$ contaminated in-volume with pure alpha, pure beta, low-energy or low-abundance gamma-emitting radionuclides. These methods will likely be difficult and costly for some radionuclides at the recommended release levels.

Impact on the quality of the $U$. S. Pb supply - The concern exists that an unintentional release of $\mathrm{Pb}$ contaminated with radioactive material could taint the public supply of $\mathrm{Pb}$. Other than health implications already discussed, the use of these materials for sensitive applications - such as shielding for radiation detector systems - would be an undesirable outcome. It would be unreasonable to consider the direct reuse of recycled products for this purpose, but dilution into the public supply with subsequent use without knowledge is unlikely but plausible. It is therefore reasonable to consider dilution factors for $\mathrm{Pb}$ pathways into the marketplace.

Referencing $\mathrm{Pb}$ information provided in Section 3.2, as well as assuming an average life for automobile batteries of 4 years, the total $\mathrm{Pb}$ inventory being used within the $\mathrm{U}$. $\mathrm{S}$. at present is estimated to be approximately $7 \times 10^{6}$ Tonnes. The quantity of $\mathrm{Pb}$ processed for public use annually is referenced to be $\sim 2 \times 10^{6}$ Tonnes. Assuming that 250 Tonnes of $\mathrm{Pb}$ will be processed by the $\mathrm{DOE}$ annually for shielding products, the ratio to existing $\mathrm{Pb}$ within the market would be $\sim 4 \times 10^{-5}$ and the ratio to annual processed $\mathrm{Pb}$ would be $\sim 1 \times 10^{-4}$. Taking a very conservative stance and assuming that $30 \%$ of the $\mathrm{Pb}$ directed for reuse in shielding containers could be inadvertently recycled through a single reprocessing facility that, by itself, handles $5 \%$ of the entire U. S. recycled $\mathrm{Pb}$ stream yields an effective dilution factor of $\sim 8 \times 10^{-4}$. Further, since $71 \%$ of the annual U.S. demand for $\mathrm{Pb}$ is met by recycling and the remaining $29 \%$ is made up from freshly mined $\mathrm{Pb}$, the effective half-time for future dilution in U.S. stocks is estimated to be 2.4 years - meaning that the bulk concentration could be halved every two to three years by reprocessing alone. 
Department of Transportation Considerations - The U. S. Department of Transportation (DOT) regulates the commercial transport of materials and has requirements for the packaging, labeling, placarding and movement of radioactive materials on public road systems. As part of these regulations, the DOT defines radioactive material in $\$ 173.403$ of $49 \mathrm{CFR}$ as "any material having a specific activity greater than $70 \mathrm{~Bq} / \mathrm{g}(0.002 \mu \mathrm{Ci} / \mathrm{g})$ ". After considering the relative magnitude of ANSI/HPS N13.12 recommendations relative to this value, it was deemed prudent to set the maximum allowable concentration for the lowest hazard class to $35 \mathrm{~Bq} / \mathrm{g}(0.001 \mu \mathrm{Ci} / \mathrm{g})$.

\subsection{Life Cycle Analysis}

Life cycle analysis, a methodology for assessing both quantitative and qualitative information important to a decision, has been applied by Oak Ridge National Laboratory to aid in pollution-prevention decision making (Yuracko, 1997a; Yuracko, 1997b; Yuracko, 1998). A limited life cycle analysis of issues relating to the disposition of DOE's radiologically contaminated $\mathrm{Pb}$ illustrates the relative advantages and disadvantages of two options: 1) directed re-use as encapsulated shielding and 2) burial as mixed waste. Issues, considered below, include cost; impacts on human health, the environment, and DOE programs/schedules; pollution prevention; resource utilization; energy conservation; public acceptance; and institutional/regulatory impacts. Please reference Figure 1 as a summary graphic supporting the following discussions.

\section{Cost}

The cost comparison of alternatives uses as a baseline the burial of 400 tons annually of contaminated $\mathrm{Pb}$ as mixed waste (MW Burial). The value of 400 tons is chosen because it represents the amount of $\mathrm{Pb}$ that may be processed annually for directed re-use in radiation shields, the single other alternative considered. Four cost elementscharacterization/survey/sorting, packaging, transportation, and disposal-are common to both alternatives. Costs for packaging in strong, tight containers are the same $(\$ 69 \mathrm{~K})$ in both alternatives, since the number of SeaLand containers required is the same in either case. Transportation costs are also considered to be essentially equivalent (at $\$ 25 \mathrm{~K}$ ), since the scrap lead must move from various DOE sites around the continental United States to a fairly central location for either recycling or burial. More extensive characterization, survey and sorting requirements for burial as mixed waste result in higher cost $(\$ 186 \mathrm{~K})$, compared with the re-use alternative $(\$ 6 \mathrm{~K})$. A significant difference is also noted in disposal costs for the two alternatives: burial as mixed waste at the EnviroCare disposal facility costs are estimated at $\$ 3.00 / \mathrm{lb}$, for a resulting total burial cost of $\$ 2,400 \mathrm{~K}$ - almost twice as expensive as encapsulation of the lead as shielding for an estimated $\$ 1.60 / \mathrm{lb}$ and a total cost of $\$ 1,280 \mathrm{~K}$.

A cost saving is present in the re-use option as an approximately $\$ 800 \mathrm{~K}$ credit against the price of commercial lead which does not have to be purchased for the construction of radiation shields. 
The cost comparison, detailed in Attachment 1 (provided by NMR for this analysis), shows that burial of contaminated $\mathrm{Pb}$ as mixed waste would cost the DOE approximately $\$ 2.7 \mathrm{M}$ annually, compared with an annual cost of $\$ 0.6 \mathrm{M}$ for re-use as encapsulated radiation shields. Directed re-use of the $\mathrm{Pb}$ in radiation shields therefore represents a $\$ 2.1 \mathrm{M}$ annual cost savings for the DOE.

\section{Human Health}

Segments of the human population at risk from exposure to $\mathrm{Pb}$ or its co-contaminants in the two alternatives under consideration are workers involved in processing the lead and fabricating the shields, and the users of the fabricated shields. Analysis provided in Section 3 of this report shows that internal exposure to ${ }^{239} \mathrm{Pu}^{(4)}$ at the Recommended Supplemental Release Limit for Group-1 radionuclides (Attachment 1) corresponds to less than a millirem committed effective dose equivalent if a worker processing the molten $\mathrm{Pb}$ at a public facility is exposed at the ACGIH time-weighted average Threshold Limit Value over a plausible part of a working year. Chemical toxicity of $\mathrm{Pb}$, present with either alternative, is clearly more significant than the radiological risk for the internal exposure scenario associated with previously processed $\mathrm{Pb}$. External radiation exposure that would result from working $10 \%$ of the time with a large amount of $\mathrm{Pb}$ contaminated with ${ }^{60} \mathrm{Co}^{(5)}$ at the Group-2 radionuclide recommended release limit would correspond to $\sim 2$ mrem committed effective dose equivalent annually. Worker protection consistent with DOE or NRC occupational radiological exposure requirements and principles for maintaining radiological exposures As Low as Reasonable Achievable (ALARA) would be expected to result in exposures significantly lower than those suggested by the worst-case scenarios used for the analyses presented in Section 3. Considering also that much of the processing (sorting, loading, transporting) of radiologically contaminated $\mathrm{Pb}$ is the same, regardless of whether the $\mathrm{Pb}$ is destined for recycle or burial, the human health impact is seen to be only marginally greater in processing and fabricating radiologically contaminated $\mathrm{Pb}$ than it is in processing and fabricating commercially available non-radiologically-impacted $\mathrm{Pb}$.

\section{Impacts on the Environment, Resources and Energy Use}

Recycling radiologically contaminated $\mathrm{Pb}$ reduces the need for new supplies of raw lead and eliminates the burial option, thereby reducing environmental pollution, maximizing the use of resources and conserving energy.

(4) Plutonium-239 is a fairly commonly encountered radiological contaminant representative of the transuranic alpha-emitting radionuclides, which have the most restrictive Annual Limits on Intake (ALI) and Derived Air Concentrations (DAC) of Group 1 (Table 1), as published by the International Commission on Radiological Protection (ICRP30, 1979; ICRP30, 1981).

(5) Cobalt-60 is a common radiological contaminant, with a relatively high specific activity, that produces highly penetrating gamma photons when it decays. Other contaminants in Group 2 (Table 1), such as Thallium-208, may have more penetrating radiations, but are not as commonly encountered. 
Even though burial practices for mixed waste are designed to greatly minimize the potential for release to the environment, re-use avoids the prospect that eventually even the best disposal practice may result in some environmental releases. Directed re-use of DOE's radiologically contaminated $\mathrm{Pb}$ is considered to be clearly more desirable environmentally because of the demonstrated toxicity of $\mathrm{Pb}$ to wildlife, as detailed in Section 3. Directed reuse of contaminated $\mathrm{Pb}$ represents maximum use of the $\mathrm{Pb}$ as a resource; burial as mixed waste makes no use whatsoever of this resource. The directed re-use option also avoids energy costs in mining, refining and transporting new sources of commercially available $\mathrm{Pb}$. The energy required to melt and cast contaminated $\mathrm{Pb}$ is the same as that required for commercial recycled $\mathrm{Pb}$.

Pollution Prevention - Directed re-use of contaminated $\mathrm{Pb}$ is clearly more desirable in meeting DOE's pollution prevention goals than the mixed-waste burial alternative for the same reasons as presented above for minimal environmental impact.

Programmatic/Schedule Impact - The large amount of radiologically contaminated $\mathrm{Pb}$ at DOE facilities represents a significant detriment to DOE programs, which must provide facilities for and support the maintenance of these unused stockpiles. They also represent, at the same time, an unused resource. The directed re-use option would greatly reduce or eliminate the stockpiles while taking advantage of the resource. Burial as mixed waste also reduces or eliminates the stockpiles, but it is likely to be completed much more slowly than directed re-use because of the significantly greater cost of burial, thereby extending the duration of programmatic support required for waste storage and maintenance.

\section{Public Acceptance}

The clear advantages of directed re-use of radiologically contaminated lead in its environmental consequences, pollution prevention, resource utilization and energy conservation indicate that strong public support for this alternative over burial as mixed waste is highly likely. The marginal advantage of burial in its human health consequences is strongly mitigated by processing and fabricating contaminated $\mathrm{Pb}$ in the directed re-use scenario under the aegis of DOE or NRC worker protection requirements, which can be expected to significantly reduce worker exposures below those estimated by the worst-case scenarios of Section 3.

\section{Institutional and Regulatory Concerns}

The proposed directed re-use of DOE's radiologically contaminated $\mathrm{Pb}$ meets all applicable regulatory requirements and is consistent with recommendations of American National Standard HPS/ANSI N13.12. This alternative avoids disposal of the $\mathrm{Pb}$ as mixed waste, a category with only limited regulatory guidance and strong antagonistic public feeling. The DOE's institutional interests are much better served by the directed re-use alternative, for which public acceptance is expected to be much more forthcoming. 


\section{Alternatives}

As discussed in Section 3, the use of release standards higher or lower than those recommended in ANSI N13.12 have been considered qualitatively. Alternative limits were rejected from further consideration since there was no obviously significant economic, environmental or health benefit to be received by doing so. Additionally, it is reiterated that the release of $\mathrm{Pb}$ for public recycle and reuse is presently prohibited by DOE policy.

\section{Summary of the Life Cycle Analysis}

A summary graphic with the results of attribute analysis related to the directed re-use and mixed-waste burial options for $\mathrm{DOE}$ radiologically contaminated $\mathrm{Pb}$ is shown in Figure 1. Directed re-use is clearly more desirable than the burial option with respect to every issue but human health impact. Burial is only marginally more desirable in terms of human health, and the difference between alternatives for this particular issue is not considered significant - especially considering the potential for significant worker radiological dose reduction, inherent in DOE and NRC radiological protection and ALARA requirements, for the directed re-use option.

\section{RECOMMENDATIONS}

Recommended release criteria for internal directed reuse of radiologically impacted $\mathrm{Pb}$ are given in Table 1 . Volume screening levels $(\mathrm{pCi} / \mathrm{g})$ were selected from Table 1 of ANSI/HPS N13.12 as recommended limits, with minor rewording and a reduction of the criteria for Group 4 due to transportation issues. Surface areal activity equivalents $\left(\mathrm{dpm} / 100 \mathrm{~cm}^{2}\right)$ were estimated - for reference purposes only-by calculating the amount of uniform surface contamination that could be on the surface of $1 / 2$-inch-thick sheets of $\mathrm{Pb}$ prior to a melt. It was assumed that all input material would remain in the final product and that the concentration could equal the recommended volumetric limit in the final product. Again, the surface equivalent values are given for reference only and are not presented as explicit limits.

Products that comply with authorized limits which, by definition, have been approved by the DOE, may be released from radiological control under the Atomic Energy Act. As such, upon approval of these limits by the Department, $\mathrm{Pb}$ products released for direct reuse may be handled without regard for radiological control as long as the radioactive burden of the lead is not increased as a result of DOE activities and the product meets all applicable surface release, recycle and disposal criteria. 


\section{REFERENCES}

40CFR, 1997

50CFR, 1997

ACGIH, 1996

AMMC, 2000

EPA/Eckerman 1988

HPS/ANSI 1999

Hubbell and Seltzer, 1997

USDHHS, 1993a
Code of Federal Regulations (July 1, 1997), Title 40, Parts 261.30-261.33 and Appendix VII, Subpart D -"Lists of Hazardous Wastes," U.S. Government Printing Office, pp. 53-86.

Code of Federal Regulations (October 1, 1997), Title 50, Part 20.21, "Migratory Bird Hunting - Hunting Methods," U.S. Government Printing Office, pp. 471-472.

American Conference of Governmental Industrial Hygienists (1996), 1996 TLVs ${ }^{\circledR}$ and BEIs ${ }^{\circledR}$ - Threshold Limit Values for Chemical Substances and Physical Agents-Biological Exposure Indices, ACGIH, Cincinnati, Ohio

American Metal Market Company (2000), Metal Statistics 2000, The Statistical Guide to North American Metals $\left(92^{\text {nd }}\right.$ ed.), Reed Elsevier, New York, NY, pp. 125-134.

Environmental Protection Agency, Eckerman K. F., Wolbarst A. B., Richardson A. C. Limiting Values of Radionuclide Intake and Air Concentration and Dose Conversion Factors for Inhalation, Submersion and Ingestion Federal Guidance Report No. 11, EPA-520/1-88-020. 1988

Health Physics Society, American National Standards Institute Surface and Volume Radioactivity Standards for Clearance-ANSI/HPS N13.12-1999 American National Standard, Health Physics Society. 1999

Hubbell, J. H. and Seltzer, S. M. (1997). Tables of X-Ray Mass Attenuation Coefficients and Mass Energy-Absorption Coefficients (version 1.02), [Online]. Available: http://physics.nist.gov/xaamdi [2000, December 29]. National Institute of Standards and Technology, Gaithersburg, MD.

U.S. Department of Health and Human Services (1993), Toxicological Profile for Lead, ATSDR/TP-92/12 (NTIS PB93-182475), National Technical Information Service, Springfield, Virginia 
USEPA, 1982

ICRP30, 1979

ICRP30, 1981

Townsend, 1999

Yuracko, 1997a

Yuracko, 1997b

Yuracko, 1998
U.S. Environmental Protection Agency (1982), An Exposure and Risk Assessment for Lead, EPA 440/4-85/010 (NTIS PB85-220606), National Technical Information Service, Springfield, Virginia

International Commission on Radiological Protection (1979), "Limits for Intakes of Radionuclides by Workers," ICRP Publication 30, Supplement to Part 1, Annals of the ICRP, Vol 3 No1-4.

International Commission on Radiological Protection (1981), "Limits for Intakes of Radionuclides by Workers," ICRP Publication 30, Supplement to Part 2, Annals of the ICRP, Vol 5 No1-6.

Townsend, T. G., Musson, S., Jang, Y.-C., Chung, I.-H. "Characterization of Lead Leachability from Cathode Ray Tubes using the Toxicity Characteristic Leaching Procedure" State University System of Florida, Florida Center for Solid and Hazardous Waste Management, Report \#99-5, 1999.

Yuracko, K. L., Hadley, S. W., Perlack, R. D., Rivera, R. G. and Curlee, T. R. (1997), "A Life Cycle Decision Methodology for Recycle of Radioactive Scrap Metal," International Journal of Life Cycle Assessment, Vol 2 No 4, pp. 223-228.

Yuracko, K. L., Hadley, S. W., Perlack, R. D., Rivera, R. G. and Curlee, T. R. (1997), "Fernald's Dilemma: Recycle the Radioactively Contaminated Scrap Metal, or Bury It?" Resources, Conservation, and Recycling, Vol 19, pp. 187198.

Yuracko, K. L., Yerace, P., Lehrter, B., and Gresalfi, M. (March 2, 1998), "Life Cycle Analysis for Pollution Prevention Decision-Making," presented at Waste Management '98, Tucson, Arizona. 
Table 1. Recommended Supplemental Release Limits

for the Directed (Controlled) Reuse of Lead in

Shielding Products by the Department of Energy ${ }^{(a)}$

\begin{tabular}{|c|c|c|}
\hline Radionuclide Group & $\begin{array}{l}\text { Recommended } \\
\text { Volume Limit } \\
(\mathbf{p}) \\
(\mathbf{p C i} / \mathrm{g})\end{array}$ & $\begin{array}{l}\text { Estimated Surface } \\
\text { Equivalent } \\
(\mathrm{dp}) \\
\left(\mathrm{dpm} / \mathbf{1 0 0} \mathrm{cm}^{\mathbf{2}}\right) \\
\end{array}$ \\
\hline $\begin{array}{l}\text { Group } 1 \text { Radium, Thorium and } \\
\text { Transuranics and associated decay } \\
\text { chains }{ }^{(\mathrm{c})}:{ }^{210} \mathrm{Po},{ }^{210} \mathrm{~Pb},{ }^{226} \mathrm{Ra},{ }^{228} \mathrm{Ra},{ }^{228} \mathrm{Th}, \\
{ }^{230} \mathrm{Th},{ }^{232} \mathrm{Th},{ }^{237} \mathrm{~Np},{ }^{239} \mathrm{Pu},{ }^{240} \mathrm{Pu},{ }^{241} \mathrm{Am} \\
{ }^{244} \mathrm{Cm}\end{array}$ & 3 & $5 \times 10^{3}$ \\
\hline $\begin{array}{l}\text { Group 2 Uranium and Selected High } \\
\text { Specific Dose Factor }{ }^{(d)} \text { Beta-Gamma } \\
\text { Emitters: }{ }^{24} \mathrm{Na},{ }^{54} \mathrm{Mn},{ }^{58} \mathrm{Co},{ }^{60} \mathrm{Co},{ }^{65} \mathrm{Zn}, \\
{ }^{90} \mathrm{Sr},{ }^{94} \mathrm{Nb},{ }^{106} \mathrm{Ru},{ }^{110 \mathrm{~m}} \mathrm{Ag},{ }^{124} \mathrm{Sb},{ }^{134} \mathrm{Cs}, \\
{ }^{137} \mathrm{Cs},{ }^{152} \mathrm{Eu},{ }^{154} \mathrm{Eu},{ }^{192} \mathrm{Ir},{ }^{234} \mathrm{U},{ }^{235} \mathrm{U},{ }^{238} \mathrm{U}, \\
\text { Natural Uranium }\end{array}$ & 30 & $5 \times 10^{4}$ \\
\hline $\begin{array}{l}\text { Group } 3 \text { Moderate Specific Dose } \\
\text { Factor }{ }^{(d)} \text { Beta-gamma Emitters: }{ }^{24} \mathrm{Na} \\
\\
{ }^{36} \mathrm{Cl},{ }^{59} \mathrm{Fe},{ }^{109} \mathrm{Cd},{ }^{129} \mathrm{I},{ }^{131} \mathrm{I},{ }^{144} \mathrm{Ce},{ }^{198} \mathrm{Au}, \\
{ }^{241} \mathrm{Pu}\end{array}$ & 300 & $5 \times 10^{5}$ \\
\hline $\begin{array}{l}\text { Group 4 Low Specific Dose Factor }{ }^{(d)} \\
\text { Beta-gamma Emitters: }{ }^{3} \mathrm{H},{ }^{14} \mathrm{C},{ }^{32} \mathrm{P},{ }^{35} \mathrm{~S}, \\
{ }^{45} \mathrm{Ca},{ }^{51} \mathrm{Cr},{ }^{55} \mathrm{Fe},{ }^{63} \mathrm{Ni},{ }^{89} \mathrm{Sr},{ }^{99} \mathrm{Tc},{ }^{111} \mathrm{In},{ }^{125} \mathrm{I}, \\
{ }^{147} \mathrm{Pm}\end{array}$ & 1000 & $1 \times 10^{6}$ \\
\hline
\end{tabular}

(a) Adapted from Table 1 of ANSI/HPS N13.12 with minor rewording. Maximum screening criterion for Group 4 was decreased to $1000 \mathrm{pCi} / \mathrm{g}$ to avoid possible classification as Radioactive Material during commercial transport on public road systems. All values have been rounded to 1 significant figure.

(b) Volume screening levels were selected as the basis for release limits. Surface limits $\left(\mathrm{dpm} / 100 \mathrm{~cm}^{2}\right)$ are for reference purposes only and were estimated by calculating how much contamination could be present on the surface of $1 / 2$-inch-thick sheets of $\mathrm{Pb}$ prior to melting by assuming that all input material will remain in the final product. Actual allowable surface contamination levels will vary depending on the form of $\mathrm{Pb}$ being processed.

(c) For decay chains, the limits represent total activity present-i.e., the activity of the parent plus the activity of all progeny.

(d) Specific Dose Factor - Used here to mean committed dose equivalent per unit intake. 


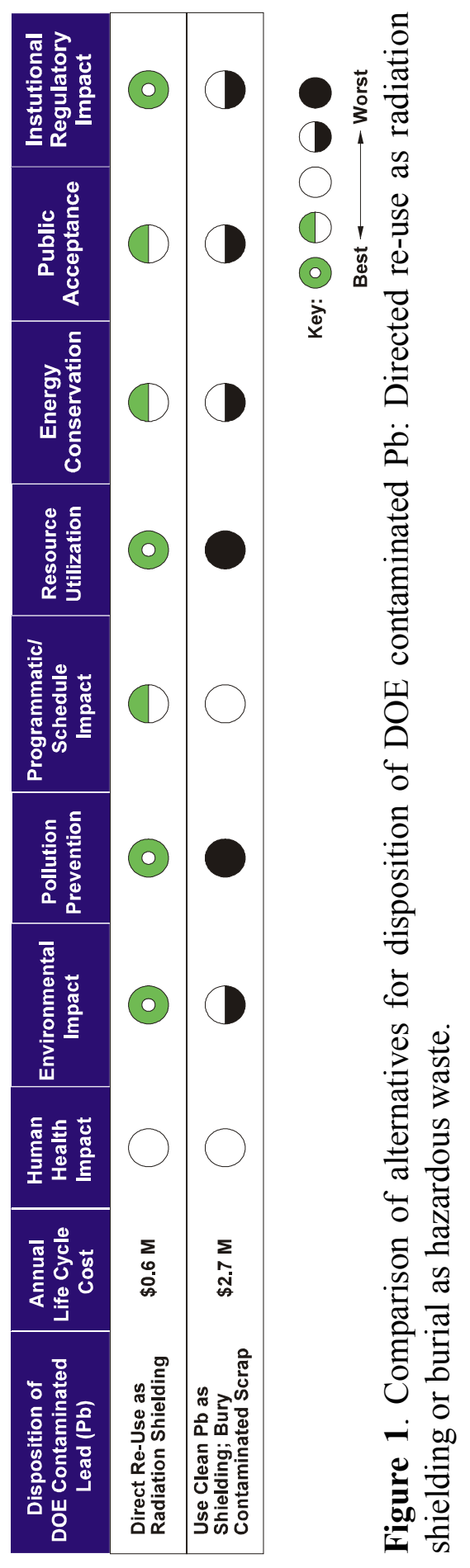


ORNL/TM-2001/36

\section{ELECTRONIC DISTRIBUTION}

E. W. Abelquist, ORISE

M. L. Bishop, DOE

J. S. Bogard, ORNL

R. L. Coleman, ORNL

C. M. R. Goddard, IT Corp.

P.Y. Lu, ORNL

ORNL Laboratory Records

ORNL Central Research Library [abelquie@orau.gov]

[bishopml@oro.doe.gov]

[bogardjs@ornl.gov]

[colemanrl@ornl.gov]

[goddardcm@oro.doe.gov]

[lupy@ornl.gov] 


\section{Appendix 1. Commercial Sector Contaminated Lead Recycling Initiative Prepared by C. M. Goddard of IT Corporation}

\section{(Projected Annual Cost Analysis)}

\begin{tabular}{|c|c|c|c|c|}
\hline \multirow[b]{2}{*}{ Characterization/Survey/Sorting } & \multicolumn{2}{|c|}{$\begin{array}{c}\text { BASELINE } \\
\text { MW Burial }\end{array}$} & \multicolumn{2}{|c|}{$\begin{array}{c}\text { RECYCLE } \\
\text { ALTERNATIVE } \\
\text { Lead Reuse } \\
\end{array}$} \\
\hline & $\$$ & 185,966 & $\$$ & 6,400 \\
\hline Packaging Costs & $\$$ & 69,300 & $\$$ & 69,300 \\
\hline Transportation Costs & $\$$ & 25,200 & $\$$ & 25,200 \\
\hline Burial / Recycle Costs & $\$$ & $2,400,000$ & $\$$ & $1,280,000$ \\
\hline Total Costs & $\$$ & $2,680,466$ & $\$$ & $1,380,900$ \\
\hline Credit for New Lead Purchase & . & & $\$$ & $(800,000)$ \\
\hline Net Total Costs & $\$$ & $2,680,466$ & $\$$ & 580,900 \\
\hline Annual Net Cost Avoided & $\$$ & $2,099,566$ & & \\
\hline
\end{tabular}

Methods of Accomplishment:

The disposition baseline for the suspect radiological contaminated lead was burial of the lead at a commercial

mixed low-level radiological waste disposal facility. This assumption was made in the absence of a defined disposition plan for the material.

The sequence of activities required to accomplish the disposal baseline are:

[1] characterize the suspect radiological contaminated lead for transport and disposal;

[2] package the lead into DOT "strong tight" shipping containers;

[3] transport the lead, via motor carrier, to the LLW disposal facility in Clive, Utah; and

[4] bury the lead at the commercial MLLW disposal facility.

The recycle alternative will be accomplished by shipping the lead to a commercial facility for Recycle/Reuse.

The sequence of activities required to accomplish the Reuse alternative are:

[1] characterize the suspect radiological contaminated lead for transport for reuse;

[2] package the lead into DOT "strong tight" shipping containers;

[3] transport the lead, via motor carrier, to the Commercial Recycle/Reuse Facility; and

[4] Melt the lead into containers and other shapes for reuse. 


\section{Commercial Sector Contaminated Lead Recycling Initiative (Projected Cost Savings Analysis)}

Given Data:

Lead, tons

Cost per pound for Lead Products

Cost factors $\&$ assumptions:

Lead sizing/sorting for disposal, $\$ / \mathrm{lb}$

Characterization for recycle, $\$ / \mathrm{lb}$

Characterization for disposal, \$/truck load

$8^{\prime} \times 8^{\prime} \times 20^{\prime}$ SeaLand size, $\mathrm{ft}^{3}$

$8^{\prime} \times 8^{\prime} \times 20^{\prime}$ SeaLand weight, lbs

$8^{\prime} \times 8^{\prime} \times 20^{\prime}$ SeaLand capacity, lbs

Maximum transportation weight, lbs

SeaLand cost, each

Transportation cost, \$/mile

Transportation distance, miles

Lead disposal density, $\mathrm{lb} / \mathrm{ft}^{3}$

Lead Reuse Cost, $\$ / 1 b$
MLLW disposal cost, $\$ / l b$

Estimate Detail

Description of Supporting Information

400

$\$ \quad 1.00$

Engineering quote

Vendor Quote

SCA report, 9-94

SCA report, 9-94

Two samples per load @ \$2523 ea

Volumetric capacity shown on typical container

Tare weight shown on typical container

Weight capacity shown on typical container

Calculation based on tare and capacity weights

Note of quotation from container vendor

E-mail from transportation manager, estimate factor

Generic mileage

Envirocare disposal contract, summary of charges

Current commercial rate

$\$ \quad 1.60$

Characterization/Survey/Sorting

lead, tons

lead, lbs

lead sizing/sorting for disposal, $\$ / \mathrm{lb}$

labor cost to size/sort lead

characterization for disposal, \$/truck load

labor cost to characterize lead for disposal

characterization for recycle, $\$ / \mathrm{lb}$

labor cost to characterize lead for reuse

Packaging Costs

lead, lbs

lead disposal density, $\mathrm{lb} / \mathrm{ft}^{3}$

total lead volume to ship, $\mathrm{ft}^{3}$

containers needed, Volume

containers needed, weight

sealand cost, each

total packaging costs

Transportation Costs

lead, lbs

number of lead shipments, ea

material weight per shipment, lbs

container weight, lbs

shipment weight, lbs

shipment weight, tons

shipping distance, miles

shipping rate, $\$ /$ mile

cost per shipment, ea

number of lead shipments, ea

total transportation costs, lead

Disposal Costs

lead, lbs

MW disposal cost, $\$ / \mathrm{lb}$

Lead Reuse cost, $\$ / 1 b$

MW disposal cost

Lead Reuse cost

Total Costs

Credit for lead purchase, $\$ / l b$

Net Total Costs

400

BASELINE - MW Burial Disposal

$\$ \quad 185,966$

$800,000[=400 * 2000]$

$80,000[=800,000 * 0.10]$

$105,966[=21 * 5,046]$

$\$ \quad 0.008$

$\$$

800,000 [ from above ]

$1,127[=800,000 * 710.00]$

1 [ = 1127/ 1170],

rounded up

$21[=800,000 / 40,000]$, rounded up

$\$ \quad 3,300$

6,300

800,000 [ from above ]

21 [ from above ]

$38,095[=800,000 / 21]$

$43,165[=38,095+5,070]$

$$
\Rightarrow \quad 21.6[=38,095 / 2000]
$$

$1,200[=800 * 1.50]$

21 [ from above ]

$25,200[=1,200 * 21]$

800,000 [ from above ]

$2,400,000$

$800,000 \Rightarrow$

$\$ \quad 3.00$

$\$ \quad 1.60$

$\begin{aligned} & => \\ & =>\end{aligned} \quad 2,400,000[=(3.00) * 800,000]$

\begin{tabular}{ccc}
$\$$ & $2,680,466$ \\
$\$$ & $2,680,466$ \\
\hline$\$$ & $2,099,566$
\end{tabular}

RECYCLE ALTERNATIVE - Lead Reuse

$800,000[=400 * 2000]$

$\$ \quad 6,400[=800,000 * 0.008]$

$\$ \quad 69,300$

Same as Disposal

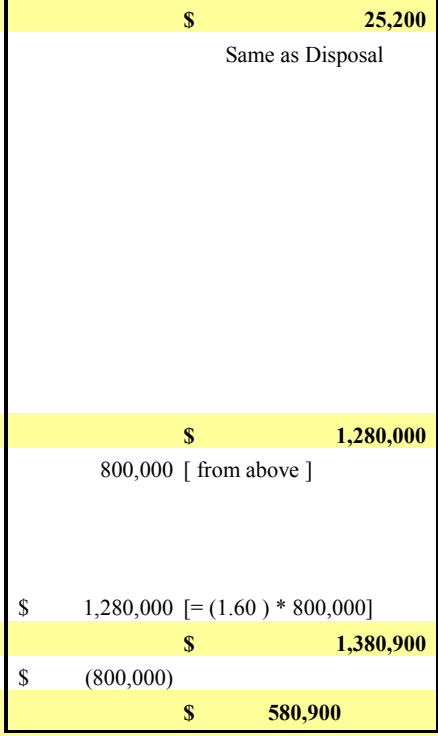

Same as Disposal

al

$\$ \quad 580,900$ 